\title{
Pre-Pandemic SARS-CoV-2 Potential Natural Immunity Among Population of Central Africa
}

Marc SOURIS ( $\nabla$ marc.souris@ird.fr)

UMR Unité des Virus Émergents (UVE Aix-Marseille Univ-IRD

Léon TSHILOLO

Centre Hospitalier Mère-Enfant Monkole

\section{Daniel PARZY}

Defideva/Altadeva - Biological Lab, Luminy Biotech, Marseille 13009 France

\section{Line LOBALOBA INGOBA}

Fondation Congolaise pour la Recherche Médicale and Faculté des Sciences et Techniques

\section{Francine NTOUMI}

Fondation Congolaise pour la Recherche Médicale and Faculté des Sciences et Techniques

\section{Rachel KAMGAING}

Centre International de Référence Chantal Biya (CIRCB)

\section{Destin MBONGI}

Centre de Formation et d'Appui Sanitaire (CEFA)

\section{Baltazar PHOBA}

Centre de Formation et d'Appui Sanitaire (CEFA)

\section{Marie-Anasthasie TSHILOLO}

Centre de Formation et d'Appui Sanitaire (CEFA)

\section{René MBUNGU}

Centre de Formation et d'Appui Sanitaire (CEFA)

\section{Martin Samuel SOSSO}

Centre International de Référence Chantal Biya (CIRCB)

\section{Nadine FAINGUEM}

Centre International de Référence Chantal Biya (CIRCB)

\section{Pierre MORAND}

UMI « Résiliences » (IRD-CIRES)

Jean-Paul GONZALEZ

Georgetown University

\section{Research Article}

Keywords: COVID-19, immunity, samples collected, SARS-CoV-2-like virus, central Africa 
Posted Date: June 24th, 2021

DOl: https://doi.org/10.21203/rs.3.rs-588697/v1

License: (c) (i) This work is licensed under a Creative Commons Attribution 4.0 International License. Read Full License 


\section{Abstract}

More than a year after the emergence of COVID-19, significant regional differences in terms of morbidity persist, showing lower incidence rates in central Africa. The work reported here aims to test for a prepandemic natural immunity among populations in this region. To identify such pre-existing immunity, sera samples collected before the emergence of COVID-19 were tested to detect IgG antibodies reacting against SARS-CoV-2 proteins of major significance. Sera samples from blood donors of France were used as control. The results showed a statistically significant difference for antibodies prevalence between the samples collected in central Africa and the control samples. Our results suggest that in the central African sub-region the populations have been potentially pre-exposed before the COVID-19 pandemic to the antigens of a SARS-CoV-2-like virus.

\section{Introduction}

More than a year after the emergence of COVID-19, significant regional differences persist, showing the lowest incidence rates in sub-Saharan Africa, Southeast Asia, and Oceania. This trend was observed at the onset of the epidemic and has been confirmed during subsequent epidemic waves (Fig. 1) [1].

Several hypotheses have been proposed to explain this situation, including among others: the morbidity and mortality counts likely to be underestimated in some low- and middle-income countries due to limited epidemiological surveillance and/or public health screening activity; the population of sub-Saharan Africa is younger with only $2.3 \%$ of the population over 65 years old, whereas people over 65 years old account for more than three-quarters of the deaths related to COVID-19 in Europe (where this population represents more than $20 \%$ of the population); more rural living conditions may reduce the spread of the disease; climatic and environmental conditions unfavorable to the virus and its spread; a natural immunity innate (nonspecific) or secondary due to previous contact with a coronavirus closely related to SARS-CoV-2 and sharing common antigenic profiles.

The objective of this present study was to identify the later hypothesis of a pre-existing natural humoral anti-SARS-CoV-2 immunity among central African population by testing sera samples from repository collected several months before the COVID-19 epidemic started. We tested the presence of a reacting antibodies against five SARS-CoV-2 proteins playing an essential role in virus attachment, fusion, entry and transmission (supplementary text). We present here our first results, obtained from 1,341 sera samples collected before January 2020 from people living in Democratic Republic of Congo (DRC), Cameroon, and Republic of Congo (ROC).

\section{Background}

SARS-CoV-2 virus pertains to the Betacoronavirus genus, which includes numerous virus species of Chiropterans. Chiropteran species are also hosts of several coronaviruses species close to the original strain of SARS-CoV-2 isolated in China [2]. SARS-CoV-1 and MERS viruses are also monophyletically 
placed with chiropteran coronavirus parental species [3]. In Cambodia and Myanmar, viruses closely related to SARS-CoV-2 were isolated from bat samples (Rhinolophus Shameli) collected before 2020 [46]. Globally, it can be observed that the spatial distribution of fruit bats matches the spatial distribution of countries with lower symptomatic circulation of COVID-19, especially in rural populations (Fig. 2) [7]. Ecology and behavior of bats, especially fruit bats (e.g.: mass frequentation of fruit orchards, roosting trees close to dwelling) may have favored the direct or indirect contact with humans. Such type of antigenic relationship and acquisition of natural immunity without morbidity, have already been observed with several viruses, including filoviruses and flaviviruses [8-10].

The long genome of Coronaviruses mainly encodes four major structural proteins: spike (S); envelope (E); membrane (M); nucleocapsid $(\mathrm{N})$. The spike-shaped transmembrane glycoprotein $(\mathrm{S})$ on the surface of the virus plays an essential role in virus attachment, fusion, entry, and transmission. It comprises two functional subunits: S1 subunit responsible for binding between the virus and the receptor; and S2 subunit (C-terminal stem) that allows fusion of viral and cellular membranes. The $\mathrm{S} 1$ subunit is divided into an $\mathrm{N}$-terminal domain (NTD) and a receptor binding domain (RBD) of the $\mathrm{C}$-terminal region responsible for binding the virus to the host cell (ACE2) receptor binding domain $[11,12]$. The nucleocapsid ( $N$ protein) is involved in the packaging of RNA during the externalization of viral particles from the infected cell and is an internal protein of the virus [13]. The $N$ protein appears more conserved across Betacoronavirus species than the S protein, while the RBD appears more conserved within the S1 unit. From the point of view of protection (i.e., neutralizing antibodies), there is a strong correlation between the levels of RBD antibodies and the neutralizing antibodies to SARS-CoV-2 in humans [14]. Also, SARS-CoV-2 genome is closely related to SARS-CoV- 1 (79.6\% genomic sequence identity), several antibodies covering all structural proteins of SARS-CoV-1 (spike, membrane, nucleocapsid, envelope) have been identified and extensively studied showing cross-reactivity with SARS-CoV-2, as well as partial cross-neutralization of spike antibodies [15]. Moreover, sera from SARS-CoV-1 convalescent or S1 CoVspecific animal antibodies can neutralize SARS-CoV-1 infection by reducing S protein-mediated SARSCoV-1 entry [16]. Finally, SARS-CoV-1 and MERS-CoV show that many fragments (S1-NTD, RBD, S2) of S protein are targets for neutralizing antibody production [17].

\section{Methods}

\section{Antibody detection}

The INNOBIOCHIPS ELISA serological test used detects the IgG antibodies targeting the N protein, the S1 protein, the RBD domain of the S1 protein, the NTD domain of the S1 protein, and the S2 protein [18]. The test values are obtained by optical density reading using a laser reader. The specificity of the test was evaluated using 25 samples positive for low pathogenic human coronaviruses (229E, OC43, NL63, HKU1) [19]. All 25 samples tested negative for all SARS-CoV-2 proteins used in the ELISA test.

\section{Data analysis}


After calculating the statistical moments and the distribution of the samples' values for each antigen, several statistical tests and calculations were performed including: For each antigen, comparison of the means (Student's T-test) and the variances (F-test) between the samples group and the "control" group; Difference between the two groups (samples and controls) considering all the five antigens was tested using Hotelling test; The control group was taken as a whole, without excluding the few suspected falsenegative samples. Calculation of the number and percentage of samples considered positive for each antigen (with confidence interval), according to the cutoff value; calculation of the number of positive samples for two or more antigens.

All data are available in the main text or the supplementary materials (2021_Results PRECOV central Africa.xlsx).

\section{Control sera collection}

The controls sera were obtained by INNOBIOCHIPS company from 189 samples from blood donors collected in Northern France, randomly selected (EFS, Etablissement Français du Sang) and tested negative for SARS-CoV-2 by PCR. These sera collection was used by the manufacturer to define the thresholds of positivity as compared to the sera collected from patients infected by SARS-CoV-2 (PCR test positive). We used this control group to establish thresholds for the absence of SARS-CoV-2-like antibodies with respect to their geographic origin while such blood donors from France are supposed to have not been in direct or indirect contact with bats. To eliminate the risk of false negatives (samples may came from donors of African or South Asian origin), for each antigen the distribution of control values was modeled. For each antigen, the PRECOV threshold value correspond to a probability equal to 0.0002. All control samples with a value for an antigen above the threshold will be considered as false negatives for this antigen.

\section{Sample sera collection}

RDC samples originated from the Monkole Hospital Center biobank (190 samples, collected in 2019 from healthy subjects from the hospital staff, from volunteers, and from young sickle-cell disease patients who are part of a study cohort), and from the ALTADEVA/Monkole biobank (383 samples, collected in 2014 and 2015 as part of a study of Plasmodium falciparum chemoresistance in the city-province of Kinshasa, in the central province of Kongo, and southwestern DRC).

The 383 tested samples from Cameroon were selected among samples received from various laboratories between June 2018 and June 2019 at the Chantal BIYA International Research Center for HIV Prevention and Management (CIRCB), as part of continual health monitoring among PLHIV. $51 \%$ of the 383 samples selected were among samples received from some Central and General Hospitals within the country. The remaining $49 \%$ were selected among samples received from peripheral healthcare facilities.

The samples from the Republic of Congo (384 tested samples) were collected by The Fondation Congolaise pour la Recherche Médicale in Southern district of Brazzaville, Madibou and in the Northern part of the country (Sangha) in the district of Bomassa, in 2016 and 2019, respectively. 
All samples were aliquoted and kept frozen as appropriate and each sample had companion data including date of collection, age, sex, and province of origin.

\section{Ethical Approvals}

All samples used in this study were collected before 2020 in the laboratories of the partner institutes from volunteer donors for diagnostic purposes. Blood samples were collected after informed consent for the use and reuse from each patient or from his or her parent/guardian in the case of minors. All experiments were performed in accordance with relevant named guidelines and regulations. All documents and samples were anonymized. For samples from DRC, ethical approval was obtained from the comité d'éthique du Centre de Formation et d'Appui Sanitaire/Centre Hospitalier Monkole(N/Ref.:

01/CEFAMONKOLE/CEL/2013). For samples from Republic of Congo, ethical approval was obtained from the comité d'éthique institutionnel de la Fondation Congolaise pour la Recherche Médicale (N/Ref.: 001/CEI/FCRM/2012 and 019/CEl/FCRM/2018). For samples from Cameroon, full approval was obtained from the IRB of the Centre International de Référence Chantal Biya.

\section{Results}

The controls samples from France blood donors tested for SARS-CoV-2 reacting antibodies are shown in Table 1. Among 189 control samples, we detected 18 samples with antibodies reacting against at least 1 antigen (9.5\%), and none sample with antibodies reacting against at least 2 antigens $(0 \%)$.

Table 1

Optical density values of the INNOBIOCHIPS ELISA test for the control samples, PRECOV threshold, and percentage of control samples above the threshold. The PRECOV thresholds were determined modeling the values distribution (Supplementary materials).

\begin{tabular}{|llllll|}
\hline Antigen (189 samples) & N & S1 & S2 & $\begin{array}{l}\text { S1- } \\
\text { RBD }\end{array}$ & $\begin{array}{l}\text { S1- } \\
\text { NTD }\end{array}$ \\
\hline Min & 0 & 0 & 0 & 0 & 0 \\
\hline Max & 17.95 & 1.40 & 13.56 & 1.10 & 5.24 \\
\hline Mean & 0.695 & 0.106 & 1.125 & 0.105 & 0.353 \\
\hline 1st quartile & 0.07 & 0.04 & 0.08 & 0.02 & 0.03 \\
\hline Median & 0.117 & 0.067 & 0.254 & 0.067 & 0.114 \\
\hline 3rd quartile & 0.31 & 0.10 & 1.13 & 0.12 & 0.28 \\
\hline Standard Deviation & 2.22 & 0.16 & 2.11 & 0.158 & 0.796 \\
\hline PRECOV threshold & 9 & 0.6 & 10 & 0.6 & 4.5 \\
\hline $\begin{array}{l}\text { Percentage and count of samples above the } \\
\text { threshold }\end{array}$ & $1.6 \%$ & $\begin{array}{l}2.1 \% \\
(3)\end{array}$ & $\begin{array}{l}1.5 \% \\
(3)\end{array}$ & $\begin{array}{l}2.6 \% \\
(5)\end{array}$ & $\begin{array}{l}1.6 \% \\
(3)\end{array}$ \\
\hline
\end{tabular}


Antibodies against the five tested SARS-CoV-2 antigens were detected in the pre-COVID samples, with differential optical density mean value for central African samples significantly higher than for the control samples (Table 2). The S1 antigen shows the highest percentage of positives: $22.2 \%$ for central Africa samples versus $2.11 \%$ for the control samples. The S2 and RBD antigens also show significantly higher rates. We find also a high significant difference with control samples $\left(p\right.$-value $\left.<10^{-6}\right)$ when all antigens were considered together.

Among the 1341 tested samples, 528 samples reacted at least against 1 antigen above the threshold (39\% vs. 9.5\% for the controls), while 173 samples reacted at least against 2 antigens above the threshold $(12.9 \%$ vs $0 \%$ for the controls).

Table 2

Samples values, obtained by differential optical density (1341 samples). For each antigen, the table indicate the distribution of values and the number of samples with value above the threshold (percentage and $95 \%$ confidence interval, count). The Student T-test p-value indicate the probability of no difference between the mean of Central Africa samples and the mean of control samples.

\begin{tabular}{|c|c|c|c|c|c|}
\hline Results (1341 samples) & $\mathbf{N}$ & S1 & S2 & S1-RBD & S1-NTD \\
\hline Minimum & 0 & 0 & 0 & 0 & 0 \\
\hline Maximum & 59.09 & 50.28 & 95.40 & 45.34 & 70.37 \\
\hline Mean & 2.77 & 1.10 & 4.33 & 0.42 & 1.22 \\
\hline Standard deviation & 6.93 & 4.06 & 10.42 & 2.20 & 4.44 \\
\hline 1st quartile & 0.19 & 0.10 & 0.14 & 0.004 & 0.03 \\
\hline Median & 0.63 & 0.21 & 0.66 & 0.08 & 0.14 \\
\hline 3rd quartile & 1.81 & 0.54 & 2.96 & 0.25 & 0.50 \\
\hline \multirow{2}{*}{$\begin{array}{l}\text { Number of samples > threshold: } \\
\%, 95 \% \text { C.I., and count }\end{array}$} & $6.9 \%$ & \multirow{2}{*}{$\begin{array}{l}22.2 \%[19.8- \\
24.2](298)\end{array}$} & $10.9 \%$ & $11.0 \%$ & $5.5 \%$ \\
\hline & $\begin{array}{l}{[5.5-} \\
8.3] \\
(93)\end{array}$ & & $\begin{array}{l}{[9.2-} \\
12.6] \\
(146)\end{array}$ & $\begin{array}{l}{[9.3-} \\
12.7] \\
(147)\end{array}$ & $\begin{array}{l}{[4.3-} \\
6.7] \\
(74)\end{array}$ \\
\hline Student T-test $p$-value & $\begin{array}{l}\mathrm{p}= \\
2.2^{\star} 10 \\
-5\end{array}$ & $p=4.2 * 10^{-4}$ & $\begin{array}{l}p= \\
1.3^{*} 10^{-5}\end{array}$ & $p=0.02$ & $\begin{array}{l}p= \\
0.003\end{array}$ \\
\hline
\end{tabular}

The results by country (Table 3 ) show higher values for Cameroon, especially for S1, S2, and S1-RBD antigens. The other antigens don't show significantly different values between countries. All values are significantly higher than control values. 
Table 3

Number of samples with value above the threshold, by country. For each antigen and each country, the table indicate the percentage and $95 \%$ confidence interval of samples with value above the threshold.

\begin{tabular}{|llllll|}
\hline Country (samples) & $\mathbf{N}$ & S1 & S2 & S1-RBD & S1-NTD \\
\hline Cameroon (383) & $5.7 \%$ & $32.4 \%$ & $18.0 \%$ & $22.2 \%$ & $6.0 \%$ \\
& {$[3.4-8.0]$} & {$[27.7-37.1]$} & {$[14.2-21.8]$} & {$[17.9-26.1]$} & {$[3.6-8.4]$} \\
\hline Congo (ROC) (384) & $7.6 \%$ & $16.7 \%$ & $8.1 \%$ & $7.3 \%$ & $5.0 \%$ \\
& {$[4.9-10.3]$} & {$[13.0-20.4]$} & {$[5.4-10.8]$} & {$[4.7-9.9]$} & {$[2.8-7.2]$} \\
\hline Congo (DRC) (574) & $7.3 \%$ & $19.2 \%$ & $7.8 \%$ & $5.7 \%$ & $5.6 \%$ \\
& {$[5.2-9.4]$} & {$[16.0-22.4]$} & {$[5.6-10.0]$} & {$[3.8-7.6]$} & {$[3.7-7.5]$} \\
\hline
\end{tabular}

\section{Discussion}

Our results are in favor of the hypothesis that some populations in Africa and potentially from other part of the World might be less susceptible to the SARS-CoV2 infection due to a pre-existing immunity triggered by other not yet identified Betacoronavirus of animal origin. Indeed, several Betacoronaviruses closed to the Sabercoronavirus cluster have been found in horseshoe bats, as well as specific antibody response to these viruses in African fruit bats [20,21].

Higher serological cross-reactivity to SARS-CoV-2 in sub-Saharan African regions than elsewhere has already been reported and attributed to higher exposure to human coronaviruses (HCoVs). Although it has been showed that cross-reactive T cells against SARS-CoV2 can be induced by Common Cold Coronavirus, SARS-CoV1 virus or eventually other animal Betacoronaviruses [22-24], this is the first time that specific antibodies against SARS-CoV2 proteins in sera collected before the SARS-CoV-2 emerged in China have been reported in central Africa. The novelty of our finding is that a stronger cross-reactivity in central African regions may come from exposure, not to HCoVs as already published [25], but to other animal coronaviruses circulating in these areas. Indeed, the specificity of the ELISA used in this work excludes reactions against congenital human coronaviruses (e.g., HCoV-NL63, HCoV-229E) and confirms that the identified antibodies react precisely against the SARS-Cov-2 proteins. We observed a stronger cross-reactivity to S1, S2 and RBD (considered specific to SARS-CoV-2) than for the N protein, considered common to Betacoronaviruses. Therefore, it can be assumed that this cross-reactivity must have been induced by a virus close (i.e., sharing spike epitopes) to SARS-CoV-2, rather than by other known human Betacoronaviruses. Indeed, the S1 subunit is the least conserved and cross-reactivity cannot be explained by exposure to the known Human CoVs while the $\mathrm{N}$ protein is the most conserved. Moreover, such crossreactivity with S1 does not quantitatively reproduced the S1-RBD or S1-NTD data. These consistently observed discrepancies can be explained by a variation of antibodies affinities to these epitopes due to a change of, either or both, the structure of the spike or their amino-acid sequence. Eventually a more consistent response with S1 could be the fact of a non-tested here CTD protein [26]. Altogether, such 
discrepancy of antibody response is in favor of an S1 belonging to a SARS-CoV-2-like virus, while all sequence of the antigens included in the commercial ELISA (INNOBIOCHIPS) were entirely based on the reference SARS-CoV-2 strain. It is also important to note that $\mathrm{S}$ and $\mathrm{N}$ protein sequences are equally divergent among coronaviruses while the $\mathrm{S} 2$ subunit is better conserved than the $\mathrm{N}$ protein.

We are aware of the limitations of this somewhat pioneering study. The next step is to conduct sensitive investigations among populations potentially exposed to wild animals and to perform back-to-back tests with the present ELISA test and with an essential SARS-CoV-2 neutralization assays to confirm the surprisingly high $\mathrm{S} 1$ cross-reactivity and the potential of the pre-pandemic antibodies to protect against SARS-CoV-2. Furthermore, if it is true that background reactivity in SARS-CoV-2 serological tests is higher, especially in central African populations, this may be due not only to widespread circulation/exposure of/to Betacoronavirus of chiropterans or other animals, but to a potential increased cross-reactivity induced by other microorganisms (e.g., malaria, tuberculosis, etc.) as previously observed [27-29].

\section{Declarations}

Data availability

All data are available as supplementary material (2021_Results PRECOV central Africa.xlsx).

Acknowledgments

INNOBIOCHIPS Company, for sharing original data and analytical process.

Funding

“Fond de crise COVID-19”, IRD (Institut de Recherche pour le Développement), Marseille, France.

Author contributions

Conceptualization: MS, JPG, PM

Methodology: MS, JPG, LT, DP

Investigation: DP, FN, LLI, RK, LT, DM, BP, MAT, RM, MSS, NF, JPG, MS

Funding acquisition: MS

Project administration: MS, PM

Supervision: MS, JPG, LT

Writing - original draft: MS, JPG

Writing - review \& editing: MS, JPG, LT, DP, RK, FN, PM 
Competing interests

The authors declare no competing interests.

\section{References}

1. WHO Coronavirus Disease Dashboard. https://covid19.who.int/ (last visited Apr.26, 2021).

2. Zhou, P. et al. A pneumonia outbreak associated with a new coronavirus of probable bat origin. Nature. 579(7798):270-273 (2020).

3. Li, W. et al. Bats are natural reservoirs of SARS-like coronaviruses. Science 310(5748):676-9 (2005).

4. Mallapaty, S. Coronaviruses closely related to the pandemic virus discovered in Japan and Cambodia. Nature 588(7836):15-16 (2020).

5. Hul, V. et al. A novel SARS-CoV-2 related coronavirus in bats from Cambodia. bioRxiv preprint 2021.01.26.428212; doi: 10.1101/2021.01.26.428212.

6. Hu, B. et all. Discovery of a rich gene pool of bat SARS-related coronaviruses provides new insights into the origin of SARS coronavirus. PLoS Pathog. 13(11):e1006698 (2017).

7. Kingdom, J., Happold, D., Butynski, T., Hoffmann, M., Happold, M., Kalina, J. Mammals of Africa, Vol. 4. Bloomsbury Publishing, 2013.

8. Gonzalez, J.P. et al. Ebola and Marburg virus antibody prevalence in selected populations of the Central African Republic. Microbes Infect. 2:39-44 (2000).

9. Becquart, P. et al. High prevalence of both humoral and cellular immunity to Zaire ebolavirus among rural populations in Gabon. PLoS One. 5(2):e9126 (2010).

10. Dos Santos, F.L., Gushi, L.T., Luiz, W.B., Amorim, J.H.. Seeking Flavivirus Cross-Protective Immunity. Front Immunol. 10:2260 (2019).

11. Lan, J. et al. Structure of the SARS-CoV-2 spike receptor-binding domain bound to the ACE2 receptor. Nature 581, 215-220 (2020).

12. Walls, A.C. et al. Structure, Function, and Antigenicity of the SARS-CoV-2 Spike Glycoprotein. Cell 181, 281-292 (2020).

13. Wang M.Y. et al. SARS-CoV-2: Structure, Biology, and Structure-Based Therapeutics Development. Front Cell Infect Microbiol. 10:587269 (2020).

14. Premkumar, L. et al. The receptor binding domain of the viral spike protein is an immunodominant and highly specific target of antibodies in SARS-CoV-2 patients. Sci. Immunol. 5(48) (2020).

15. Bates, T.A., Weinstein, J.B., Farley, S., Leier, H.C., Messer, W.B., Tafesse, F.G. Cross-reactivity of SARSCoV structural protein antibodies against SARS-CoV-2. Cell Reports 16;34(7):108737 (2021).

16. He, Y. et al. Cross-neutralization of human and palm civet severe acute respiratory syndrome coronaviruses by antibodies targeting the receptor-binding domain of spike protein. J. Immunol. 176, 6085-6092 (2006). doi: 10.4049/jimmunol.176.10.6085. 
17. Jiang, S., Hillyer, C., Du, L. Neutralizing Antibodies against SARS-CoV-2 and Other Human Coronaviruses. Trends Immunol. 41(5):355-359 (2020). Erratum in: Trends Immunol. 2020 Apr 24.

18. INNOBIOCHIPS. Information for Use CoViDiag: Version 1.3. Available online: https://www.innobiochips.fr/ applications/covidiag (accessed on 14 February 2021).

19. Bohn, M.K. et al. IFCC interim guidelines on serological testing of antibodies against SARS-CoV-2. Clin. Chem. Lab. Med. 58(12): 2001-2008 (2020). doi: 10.1515/cclm-2020-1413

20. Nziza, J. et al. Coronaviruses Detected in Bats in Close Contact with Humans in Rwanda. EcoHealth 17, 152-159 (2020). doi: 10.1007/s10393-019-01458-8.

21. Müller, M.A et al. Coronavirus antibodies in African bat species. Emerg Infect Dis. 13(9), 367-1370 (2007). doi: 10.3201/eid1309.070342.

22. Mateus, J. et al. Selective and cross-reactive SARS-CoV-2 T cell epitopes in unexposed humans. Science 370: 89-94 (2020). doi: 10.1126/science.abd3871.

23. Braun, J. et al. SARS-CoV-2-reactive T cells in healthy donors and patients with COVID-19. Nature 587, 270-274 (2020). doi: 10.1038/s41586-020-2598-9.

24. Le Bert, N. et al. SARS-CoV-2-specific T cell immunity in cases of COVID-19 and SARS, and uninfected controls. Nature 584 (7821):457-462 (2020). doi: 10.1038/s41586-020-2550-z.

25. Tso, F.Y. et al. High prevalence of pre-existing serological cross-reactivity against severe acute respiratory syndrome coronavirus-2 (SARS-CoV-2) in sub-Saharan Africa. Int J Infect Dis. 102:577583 (2021). doi: 10.1016/j.jij.2020.10.104.

26. Van Elslande, J. et al. Antibody response against SARS-CoV-2 spike protein and nucleoprotein evaluated by four automated immunoassays and three ELISAs. Clin. Microbiol. Infect. 26(11):1557.e1-1557.e7 (2020). doi: 10.1016/j.cmi.2020.07.038.

27. Ng, K.W. et al. Preexisting and de novo humoral immunity to SARS-CoV-2 in humans. Science 370(6522):1339-1343 (2020). doi: 10.1126/science.abe1107.

28. Stettler, K. et al. Specificity, cross-reactivity, and function of antibodies elicited by Zika virus infection. Science. 353(6301):823-6 (2016).

29. Welsh, R.M. Che J.W., Brehm M.A., Selin L.K. Heterologous immunity between viruses. Immunol Rev. 235(1):244-66 (2010).

\section{Figures}




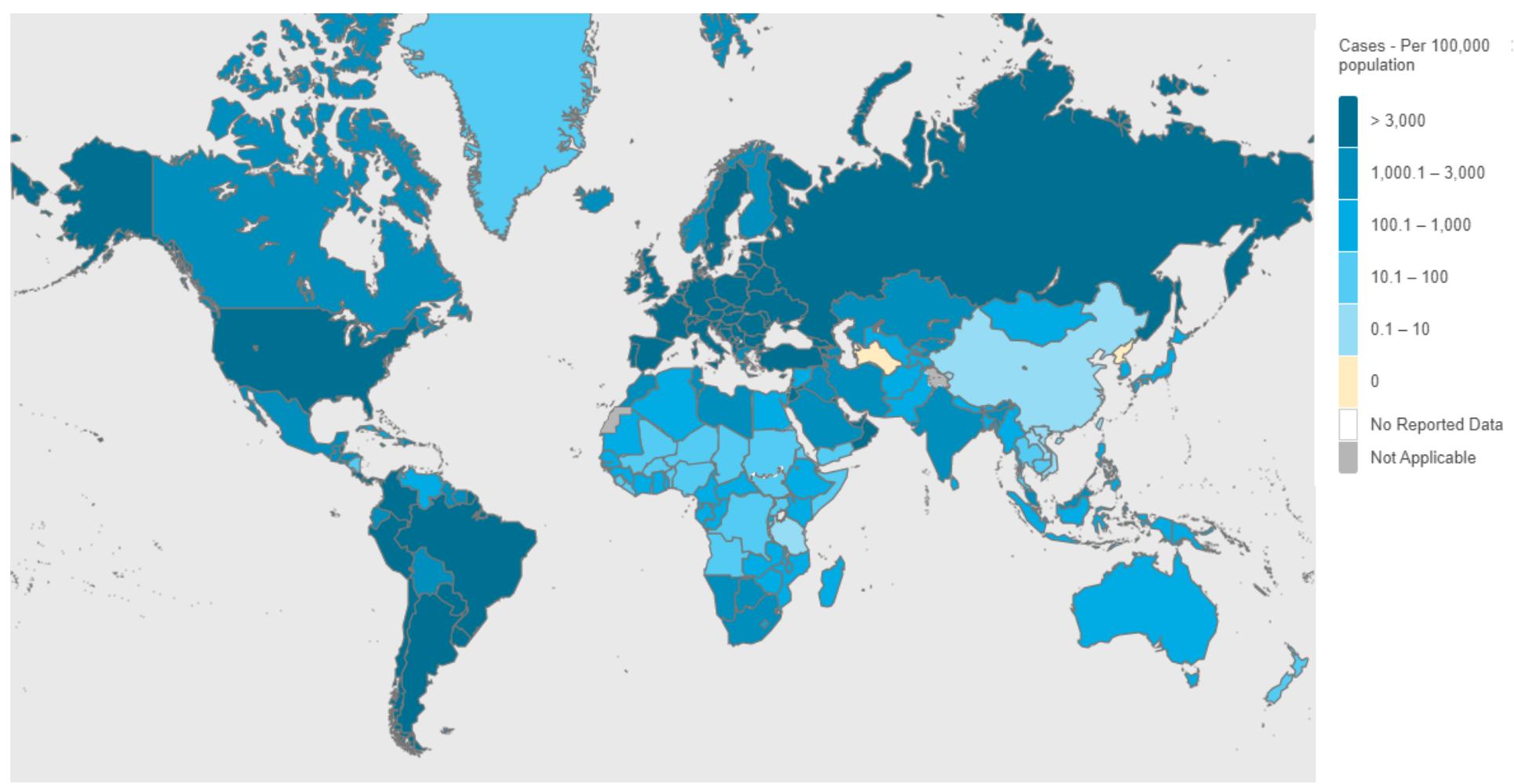

Figure 1

COVID-19 incidence in the World, as for April 19, 2021. Note: The designations employed and the presentation of the material on this map do not imply the expression of any opinion whatsoever on the part of Research Square concerning the legal status of any country, territory, city or area or of its authorities, or concerning the delimitation of its frontiers or boundaries. This map has been provided by the authors.

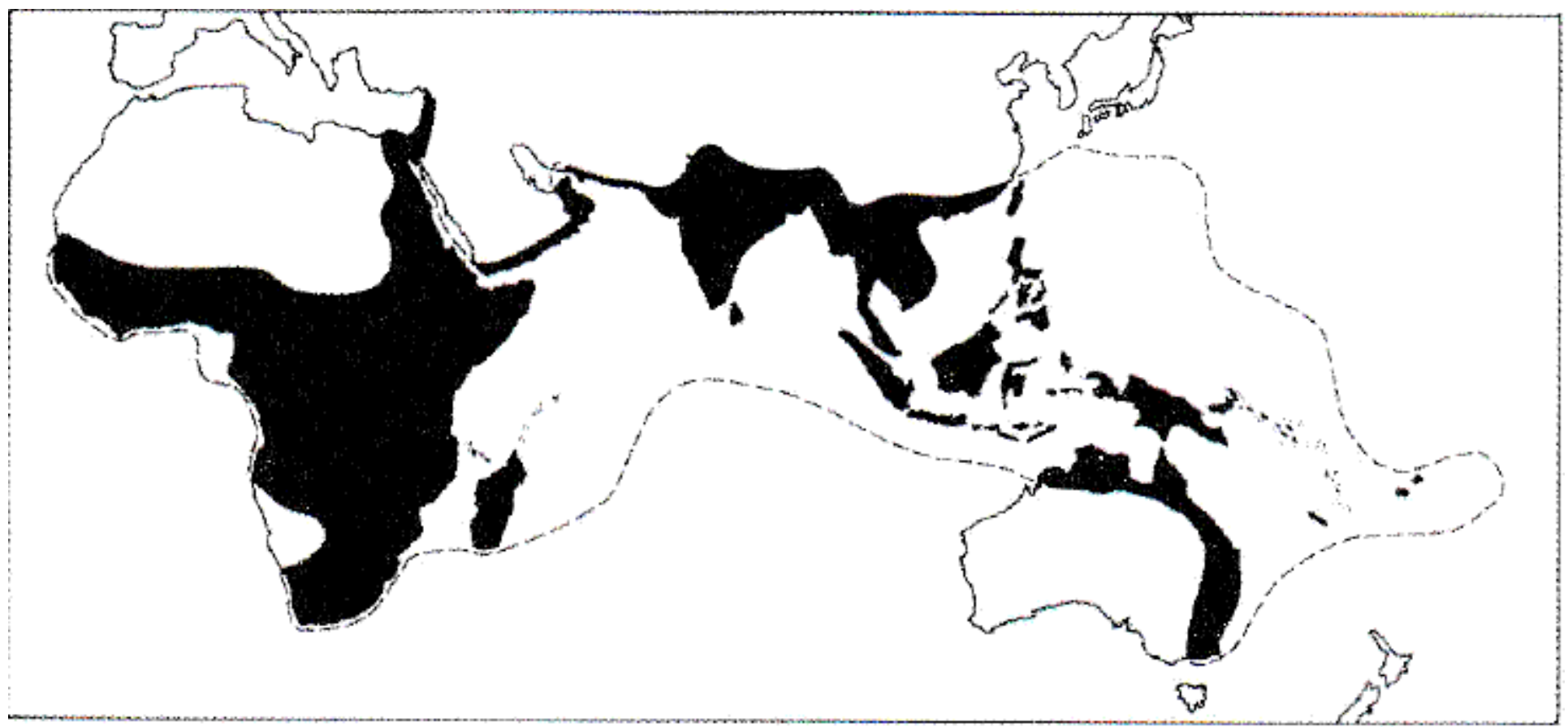

Figure 2 
Fruit bats geographic distribution. Note: The designations employed and the presentation of the material on this map do not imply the expression of any opinion whatsoever on the part of Research Square concerning the legal status of any country, territory, city or area or of its authorities, or concerning the delimitation of its frontiers or boundaries. This map has been provided by the authors. 